\title{
Assessment and control of geodynamical risks under the conditions of a rock-bump hazardous complex deposit
}

\author{
Igor Rasskazov ${ }^{1}$, Alexander Sidlyar ${ }^{1 *}$, Andrei Tereshkin ${ }^{1}$ and Andrei Golosov ${ }^{2}$ \\ ${ }^{1}$ Mining Institute FEB RAS, 51 Turgenev st., Khabarovsk, 680000, Russia; \\ ${ }^{2}$ Far Eastern Federa lUniversity, 690014, Vladivostok, Russia
}

\begin{abstract}
Research has been carried out to study the peculiarities of rockbump hazards and induced seismic manifestations at the Nikolaevskoe deposit, and their close correlation with the tectonic structure of the rock massif has been established. In order to strengthen control over the rock-bump hazard in the TN-3 high-angle fault, in 2019 the observation network was expanded and continuous seismoacoustic monitoring of the rock mass at the deep levels of Nikolaevskoe deposit was organized. Monitoring data is verified by local geoacoustic method using the portable device "Prognoz L". The results of the monitoring revealed major acoustically active zone with the main amount of seismic and acoustic events recorded during the last 5 years and occurring dynamic rock pressure manifestations. Nikolaevskoe deposit was the site of execution of the industrial experiment on regional discharge of a potentially rock-bump hazardous section of a shock blasting massif.
\end{abstract}

Key words: rock-bump hazard, induced seismicity, rock bumps, tectonic structure, seismoacoustic monitoring, acoustically active zone, shock blasting

\section{Introduction}

In the Far Eastern region of Russia, as in many other mining areas, the development of deposits takes place under increasingly complex mining, geological and geomechanical conditions. When conducting underground mining operations a serious problem is presented by dynamic rock pressure manifestations, the most dangerous forms of which are destructive rock and rock tectonic bursts, as well as induced earthquakes, which can have catastrophic consequences [1-6].

In recent years induced seismicity has been increasingly manifesting in areas with intensive mining as a reaction of the natural environment to the disturbance of its balance. Under such conditions ensuring the acceptable level of geodynamic risks by continuous monitoring of changing geophysical fields, geomechanical processes and sites of breakdown, including deep in the massif, is of key importance. It is necessary to study in depth the processes of self-organizing of the block-hierarchical structure of the massif and other effects and phenomena closely connected with induced seismicity and formation of the sites of catastrophic events.

\section{*Corresponding author: alex-igd@mail.ru}


In the Far East region there is a whole range of ore deposits being developed, which are prone to and dangerous in terms of pressure bumps [1]. In recent years the geomechanical situation at Nikolaevskoe polymetallic deposit (the deepest in the Far East), located in the Eastern Primorye, grew more complicated, and the number of large dynamic rock pressure manifestations increased against the background of additionally recorded manifestations of induced seismicity. The deposit has a complex geological structure and is located at the tectonically active area of the Earth's crust [7, 8]. The purpose of the research is to assess the main causes and factors determining the rock-bump hazard of Nikolaevskoe deposit and to test measures to reduce geodynamic risk when conducting mining operations at great depths near the active faults.

\section{Analysis of factors of dynamic rock pressure manifestations}

There are comprehensive studies of rock bumps involving the use of instrumental methods, including geomechanical, geoacoustic, deformation one and some others, being conducted at Nikolaevskoe deposit [9-12]. Important information on the state of the rock-bump hazard massif was obtained using the multichannel seismic acoustic system "Prognoz ADS" and the device for local control of rock-bump hazards "Prognoz L", developed by the Mining Institute of Far Eastern Branch of Russian Academy of Sciences.

The Prognoz-ADS automatic overburden pressure monitoring system (AOPMS) has been used for geomechanical monitoring at Nikolaevskoe deposit since 2011. At present, the AOPMS monitoring network includes 34 digital receiving transducers installed in the wells drilled in mine workings at reference levels of $-307 \mathrm{~m},-323 \mathrm{~m},-348 \mathrm{~m},-360 \mathrm{~m},-380$ m, -390 m, -406 m, $-420 \mathrm{~m}$ and $-433 \mathrm{~m}$.

Between 2011 and 2019, 48 cases of major dynamic rock pressure manifestations were registered at the deposit, ranging from shakes to rock and rock tectonic bursts, as well as numerous manifestations of induced seismicity. In 2019, 9 shakes were recorded in the area, which exceeds the figures for 2017 and 2018 and indicates the worsening of the geomechanical situation. The analysis of the positional relation of major geodynamical events (including shakes in the depth of the massif) registered at Nikolaevskoe deposit shows that their significant part (89\%) is limited to the sites of active faults, dyke-like bodies, tectonic block boundaries and other elements of the geological structure disturbed by mining operations (Fig. 1).

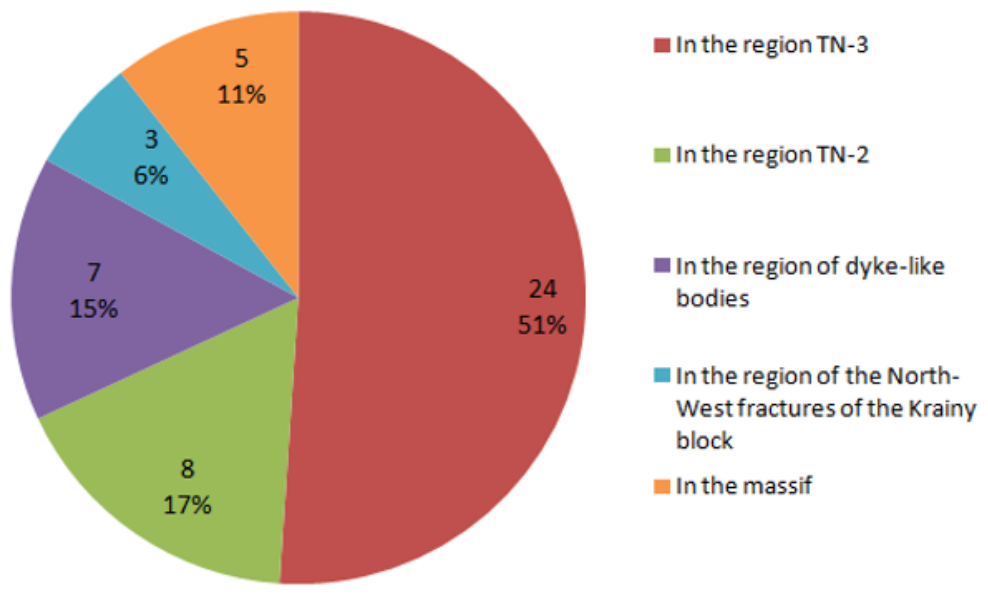

Fig. 1. Diagram reflecting the confinement of major geodynamical events to various elements of Nikolaevskoe deposit tectonic framework 
The greatest number of events (24 events, $50 \%$ ) is located in the geodynamically active fault zone TN-3, 8 events (17 \%) - along the TN-2 fault, 7 shakes (15\%) - in the region of dyke-like bodies and 3 shakes (6\%) - near the North-West fractures of the Krainy block. Only 5 shakes (11\%) were registered in the depth of the rock massif outside the fault zones (see Fig. 1).

\section{Results of Seismoacoustic Monitoring}

Due to the deepening of mining operations and in order to strengthen control over the rockbump hazards of the sections of the massif near the high-angle fault TN-3, in the area of which mining operations are being carried out, in 2019 the monitoring network was expanded and 8 additional geophones were installed in the mine workings at the reference levels of $-390 \mathrm{~m}$ and $-420 \mathrm{~m}$.

In 2019 broken workings at the Nikolaevskoe deposit were performed mainly on the southern and northern flanks of the Vostok-1 ore zone: block Sever-8 on the reference levels -390 m, -406 m, -420 m; block 45 on the reference levels -375 m, -390 m, -406 m; block 55 on the reference level $-375 \mathrm{~m}$, as well as in the area of Kharkovskaya ore zone (chamber 3, 4, block Krainy on the reference level -327 m, -348 m, -360 m).

In total, 21105 seismic and acoustic events with a total energy of 1662 thousand Joules were registered at the deposit over the period from December 2018 to November 2019. The highest activity was observed in the second and the third quarter of 2019 in the area of the tectonically active fault $\mathrm{TN}-3$.

Seismoacoustic activity at the deposit as a whole was low during the first quarter, but since March it began to grow in intensity and a number of strong dynamic rock pressure manifestations have been registered. Thus, 4 tremors were registered at the reference level of $-420 \mathrm{~m}$ during the development of the Sever-8 block.

The first shake was registered on March 25, 2019 at 18:53 in the limestone massif with a system of cracks in the north western, north eastern and latitudinal directions with a strong rocking effect in the area of the OPB block at a reference level of -433 meters. Another 3 shakes were recorded on March 28, 2019 at 07:22 after blasting operations. The first of them was registered with $1706 \mathrm{~J}$ in the Sever-8 block at the $-409 \mathrm{~m}$ mark. During the next two minutes two more shakes were recorded at a deeper depth (at $-491 \mathrm{~m}$ and $-515 \mathrm{~m}$ mark). Subsequently, an increase in seismoacoustic activity was also observed over the IIIII quarters during the development of block 45 .

Since June 9, 2019 a sharp increase of acoustic activity was observed at the reference level of $-406 \mathrm{~m}$ in the area of the haulage roadway $45-2$ in close proximity to the tectonically active fault TN-3 (Fig. 2). The increase in activity coincided with the transition of the chamber 2 of block 45 to the reference level of $-406 \mathrm{~m}$. 


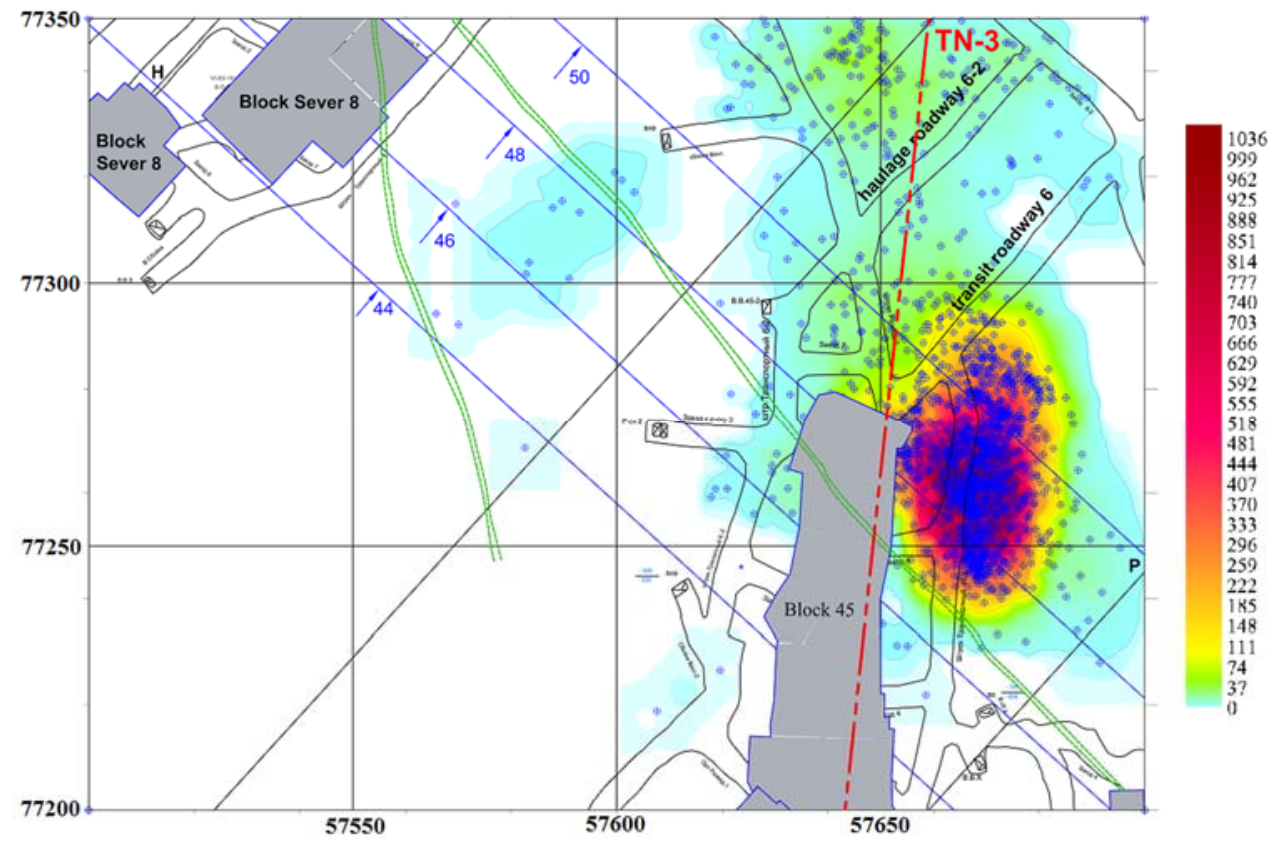

Fig. 2. Map of acoustic activity and shakes registered from June to September 2019 at Nikolaevskoe deposit projected on the reference level of $-406 \mathrm{~m}$.

In the period from June 15, 2019 to June 26, 2019 the geomechanical monitoring system "Prognoz-ADS" identified in this region a large acoustically active zone (AAZ), within which about 850 acoustic emission events (AE-events) with a total energy of 19395 J were registered (see Fig. 2).

\section{Conducting experimental studies on regional discharge of a rock massif}

The large acoustically active zone identified during the monitoring process suggests a high probability of a powerful geodynamical event, especially since a similar event has already taken place in this area before (March 28, 2020 07:21). In order to perfect the efficient methods of decreasing the geodynamic risk experimental-industrial works on regional discharge of the massif area near the chambers 1 and 2 of block 45 were carried out. According to the monitoring data it was where the process of formation of the rock bump focal point has been observed.

In order to carry out the preconditioning of the massif using the concussion blasting method in accordance with the project, two drill rings of 89-105 mm diameter were drilled in the area of the identified acoustically active zone with the ring spacing of $5 \mathrm{~m}$ (Fig. 3A). The squalor to destress the massif was made on June 25, 2019 at 07:11. According to the monitoring data after conducting the blasting operations a short-term increase in acoustic activity was observed, after which acoustic activity gradually decreased almost to the background level within 10 days from June 26, 2019 (Fig. 3b and 3c). 
$a$

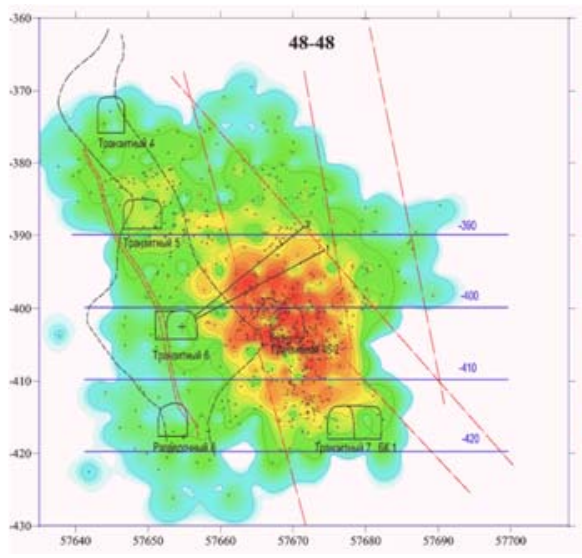

N, AE-events $b$

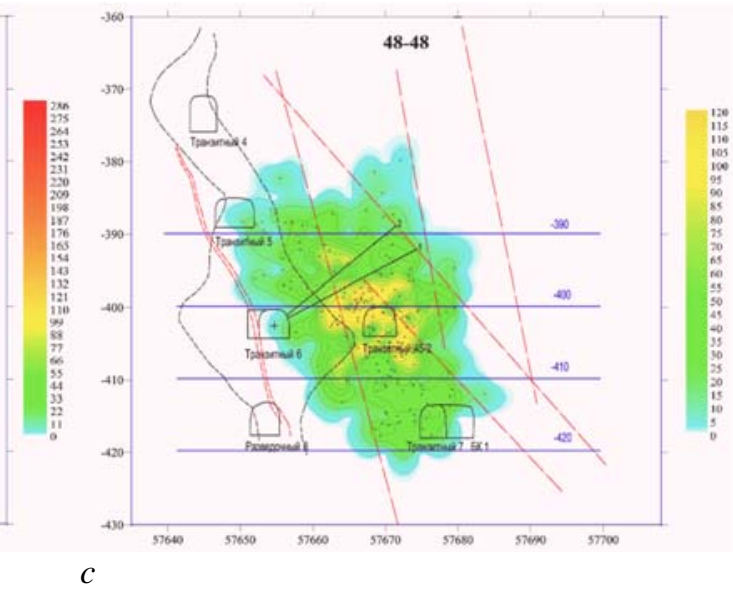

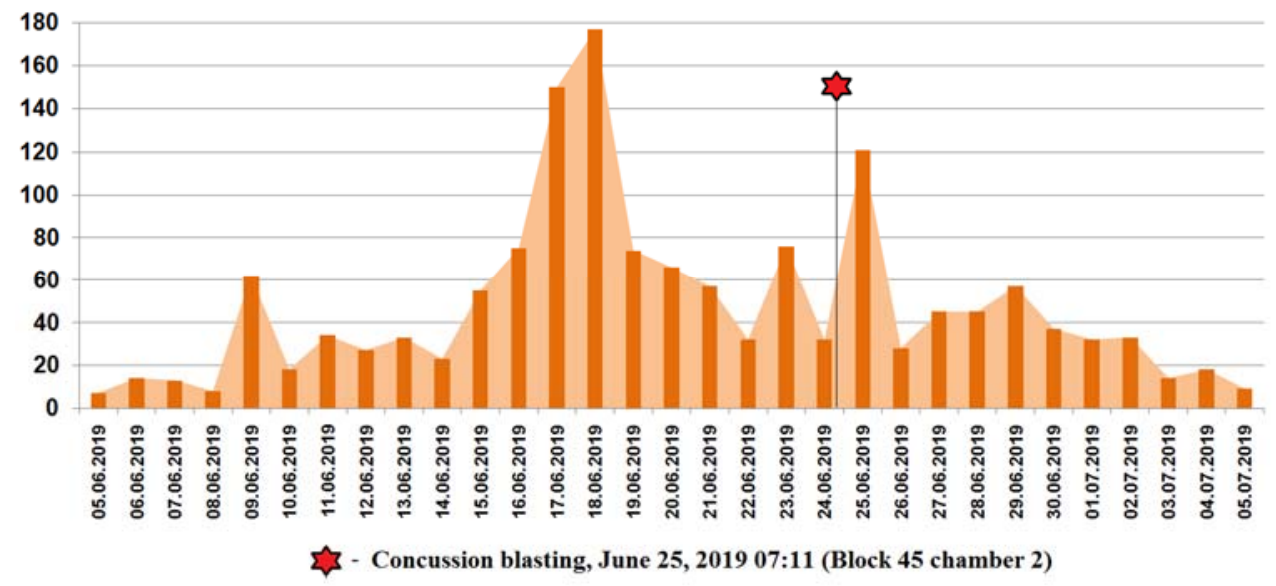

Fig. 3. Maps of acoustic activity for the 10 days before $(a)$ and after $(b)$ the concussion blasting at Nikolaevskoe deposit and a chart of the acoustic emission events in the AAZ area (c)

Efficiency of the preconditioning measures was also assessed with the help of the rockbump hazards local control device "Prognoz L", developed by the Mining Institute of Far Eastern Branch of Russian Academy of Sciences, which allows registering various parameters of AE pulses, such as frequency, amplitude, duration, arrival time and others [13]. The local control device "Prognoz L" employs a number of algorithms to identify the impulses of natural acoustic emission against the background of anthropogenic noise.

\section{Conclusions}

1. The results of researching the peculiarities of rock-bump hazards and induced seismic manifestations at Nikolaevskoe deposit established their close correlation with the tectonic structure of the rock massif under the boundary state of stress. More than $89 \%$ of the shakes registered since 2011 at Nikolaevskoe deposit are confined to the elements of the tectonic structure, and especially - to the TN-3 zone of active high-angle fault with associated fracture sets and mainly north-west steeply dipping dyke-like bodies.

2. According to the data of geomechanical monitoring a large acoustically active zone was identified in Nikolaevskoe deposit massif near the active fault TN-3, within which 
about 850 acoustic emission events with total energy of $19395 \mathrm{~J}$ were registered. Data analysis indicates the formation of a hazardous geodynamical event focal point here.

3. In order to perfect the efficient methods of decreasing the geodynamical risks, experimental-industrial works on regional discharge of the massif area near the chambers 1 and 2 of block 45 were carried out using concussion blasting. The efficiency of the performed explosive discharge of the rock massif section, which ensured the reduction of acoustic activity to a safe level within 10 days, has been established.

\section{References}

1. I.Yu. Rasskazov, Control and management of rock pressure at the mines of the Far East region (Moscow: Gornaya Kniga Publishing House, 2008)

2. A.V. Lovchikov, Journal of Mining Science, 4, 68-73 (2013)

3. Williams Stroud S.C. Earth Stress and Seismic Hazard from the Size-Frequency Distribution of Seismic Events // Proc. of 51st Rock Mechanics. Geomechanics Symposium (California, San-Francisco: American Rock Mechanics Association, 25-28 June,2017), 544-550 (2017)

4. Marcak Henryk, Mutke Grzegorz, J. Seismol, 17(4), 1139-1148 (2013)

5. Manchao H., Fuqiang R., Dongqiao L., International Journal of Mining Science and Technology, 28(5), 829-837 (2018)

6. V.V. Adushkin, S.V. Turuntaev, Technogenic seismicity - induced and triggered (Moscow: IDG RAN, 2015)

7. I.Yu. Rasskazov, B.G. Saksin, V.I. Usikov, M.I. Potapchuk, Gornyi Zhurnal, 12, 13-19 (2016)

8. L.I. Rogulina, O.L. Sveshnikova, Geology of ore deposits, 1, 67-82 (2008)

9. Geomechanical fields and processes: experimental and analytical studies of the formation and development of focal zones of catastrophic events in mining and natural systems (Novosibirsk, Publishing house of the SB RAS. Vol. 1. - 2018; Vol. 2. - 2019).

10. I.Ju. Rasskazov, B.G. Saksin, P.A. Anikin, A.V. Gladyr, M.I. Potapchuk, V.I. Usikov, A.A. Tereshkin \& A.V. Sidljar, Geomechanics and Geodynamics of Rock Masses: Proceedings of the 2018 european rock mechanics symposium, 2, 1501-1506 (2018)

11. A.A. Tereshkin \& M.I. Rasskazov, Geomechanics and Geodynamics of Rock Masses: Proceedings of the 2018 european rock mechanics symposium, 2, 1627-1632 (2018)

12. D.V. Sidorov, M.I. Potapchuk, A.A. Sidlyar, Notes of a mining institute, 234, 604-611 (2018)

13. I.Y. Rasskazov, D.S. Migunov, P. A. Anikin, A.V. Gladyr, A.A. Tereshkin, D.O. Zhelnin, Journal of Mining Science, 51(3), 614-623 (2015) 